\title{
Un probable cambio paradigmático en los Estados Unidos
}

\section{F. Duque}

Ahora, a finales de septiembre de 2008, el mundo ve con asombro el comienzo del fin de una época histórica. El gobierno de los ricos, por los ricos, y sólo para los ricos iniciado a finales de los años 70’s del siglo pasado, está llegando a su fin en los Estados Unidos de América. Después de casi 40 años, en que el ingreso y la riqueza nacional se ha ido gradualmente concentrando en los súper ricos (y en perjuicio del ingreso y la riqueza de las grandes mayorías); ahora se llevan varios meses en que esta tendencia se ha acelerado exponencialmente. El Estado se ha dedicado ha salvar a los capitalistas de Wall Street y se ha olvidado de los millones de pobres que están perdiendo sus casas y sus empleos. Para colmo de los colmos, ahora pretende liberar a los ricos de deudas incobrables por un monto superior a los 700.000 millones de dólares. Este intento por privatizar las ganancias y socializar las pérdidas ha sido rechazado en primera instancia por el Congreso Estadounidense El probable triunfo del senador Obama en las próximas elecciones de Noviembre, puede que inicie a nivel federal y estatal un cambio radical a la democracia participativa. Es decir, un gobierno favorable para todos, de todos y para el bien común.

En Wall Street, ya no queda ningún banco de inversión privada que controle las finanzas de los Estados Unidos. El control del crédito y las finanzas ha pasado, de un pequeño pero poderoso grupo de inversores privados, al Congreso de los Estados Unidos. De los diputados y senadores depende ahora si la crisis financiera se transforma en una crisis económica de catastróficas consecuencias para USA y el mundo, o si el sistema se estatiza suficientemente a tiempo para salvar la economía.

¿Cómo se ha caído en este abismo? Muchos observadores señalan que la elite plutocrática estadounidense a partir de 1970, injustamente, ha distribuido a su favor la riqueza y el ingreso nacional y al mismo tiempo, ha empobrecido a la inmensa mayoría de la población. Esta política regresiva y reaccionaria fue responsable en parte por la falta de demanda real que creo las crisis de estancamiento e inflación en los años 70`s y 80`s del siglo pasado. Para resolver este problema llamado debilidad estructural de la demanda, la elite plutocrática inventó con inteligencia maquiavélica el crédito masivo y fácil. Tarjetas de crédito para el consumo cotidiano y préstamos sin respaldos para gastos mayores como la adquisición de viviendas o automóviles. Pero además de inteligencia había corrupción capitalista. Las tarjetas de créditos ocultaban cobros usurarios y los créditos para comprar casas requerían pagos mensuales pequeños en los primeros tres o cuatro años, para luego aumentar drásticamente en los años siguientes .

Como era previsible, la burbuja de viviendas explotó en el 2007 y después de ello, se ha producido la miseria de millones de propietarios que han tenido que devolver sus casas a los bancos. Estos a su vez, no han podido cubrir las enormes pérdidas y han quebrado unos tras otros como una fila de dominós colapsando. Para evitar que la crisis financiera se transforme en crisis económica, el Estado ha debido intervenir, tratando de crear mayor liquidez monetaria, a fin de evitar la paralización del crédito y del consumo. No obstante, los esfuerzos realizados a la fecha no han dado los resultados esperados. Cientos de miles de millones de dólares se han introducido en el mercado. Primero se entregó directamente dinero a las familias estadounidenses, las que han recibidos pequeños "regalos monetarios" de parte del Estado. Como esto no funcionó adecuadamente, el Estado ha abierto nuevas líneas de créditos para los bancos, ha ayudado a comprar bancos en quiebra y finalmente, ha

${ }^{1}$ Doctor en Ciencia Política Universidad de California (Los Ángeles). Trabajó por 20 años como jefe de proyectos de Naciones Unidas en el área del desarrollo de la Administración Pública en Centro América, África y Asia. Actualmente se desempeña como profesor titular en Ciencias Política en la Universidad de Los Lagos, Campus Chinquihue. Ubicación: Camino Chinquihue Km 6 - Puerto Montt, Chile . E-mail: fduque@ulagos.cl. 
optado por hacerse dueño directo de instituciones con problemas agudos. En otras palabras, se ha optado por una política estatista y de nacionalización de parte importante del sistema bancario.

Pero aún con toda esta gigantesca intervención estatal, los resultados no son los esperados y la economía estadounidense se encuentra paralizada y amenaza con empezar a retroceder para atrás aceleradamente. En agosto pasado, antes de los masivos despidos del sistema financiero, el desempleo ya estaba en $6.1 \%$ o sea, casi al nivel sufrido durante la última recesión o también llamada "burbuja de las empresas electrónicas". La reducción del ingreso de las grandes mayorías (ahora para tener un ingreso familiar con poder adquisitivo similar al de los años 60’s se necesitan que tanto el marido como la esposa trabajen), y la contracción del crédito popular en los últimos meses, ha producido una verdadera revolución pacífica en los Estados Unidos. A consecuencia de ella, es altamente probable que un ciudadano negro gane la presidencia del país. El estadounidense promedio es altamente pragmático y ante un futuro colapso de su economía familiar, está dispuesto a olvidar su racismo ancestral. Obama es un genuino representante que defiende los intereses de la clase media y proletariado estadounidense.

Su programa de gobierno incluye medidas para transformar la política y economía federal de una plutocracia oligárquica a una verdadera democracia participativa. El candidato demócrata pretende bajar los impuestos de la clase media y proletaria y subir los impuestos de los ricos o sea, todos aquellos que ganen 250 mil dólares o más al año. Además, promete ahorrar los enormes recursos que se están gastando tanto en la producción de armamentos como en la guerra de Irak. También planea eliminar las grietas impositivas de los ricos, eliminar subsidios al gran empresariado y revisar la voluminosa ayuda externa a países tales como Egipto y Pakistán. Con los fondos que pretende sacar a los ricos y los ahorros presupuestarios, Obama pretende mejorar la salud, la educación y la vivienda del pueblo y, al mismo tiempo, iniciar un enorme programa de inversiones públicas en infraestructura y en energías alternativas que reemplacen la gigantesca dependencia del petróleo extranjero. Al mismo tiempo pretende crear cargos bien remunerados para millones de ciudadanos. Una gran cantidad de ciudadanos al parecer instintivamente temen que los republicanos no podrán resolver adecuadamente la gigantesca crisis que se avecina. Aún está en la memoria colectiva el recuerdo de crisis económica pasadas. Tales como las corridas de bancos del siglo XIX, la gran crisis de 1912 a 1913, la crisis que siguió al fin de la primera guerra mundial y finalmente la peor de todas la crisis, la de 1929. En todas las crisis anteriores a la depresión del 29, el dilema del capitalismo clásico fue el desequilibrio entre exceso de oferta y débil demanda. Estas crisis finalmente se resolvieron en forma sumamente penosa para la mayoría. En otras palabras se dejó que la mano invisible del mercado resolviera la situación castigando despiadadamente a los más pobres. Por el contrario en los años 30' después de los fracasos del presidente republicano Hoover, el presidente demócrata Roosevelt, se saltó el sistema financiero y creó trabajo bien remunerado para millones de sub-empleados y cesantes. El gigantesco programa de obras públicas, particularmente la construcción de grandes carreteras y la electrificación del país fueron las palancas maestras que permitieron al país salir del abismo depresivo. Son estas mismas políticas Keynesianas las que pretende implementar Obama a partir de Enero del 2009.

La evolución histórica de la política estadounidense se puede analizar utilizando la teoría de la anaciclosis elaborada por Maquiavelo hace ya varios siglos atrás. Esta es una teoría que describe, explica y trata de predecir la marcha de la historia y por lo tanto, es una visión teleológica. Ella señala que por lo general, todas las sociedades humanas se mueven de formas de gobiernos tradicionales, a formas de gobiernos más participativos y democráticos. Es decir, del gobierno de uno, se pasa al gobierno de unos pocos y se termina con el gobierno de todos.

El proceso evolutivo se inicia con el gobierno del filósofo rey que gobierna para todos es decir, para el bien común. Esta es la forma llamada MONARQUÍA y es una forma benigna que sobrevive mientras las dinastías monárquicas mantienen niveles éticos adecuados. Cuando este gobierno benigno se corrompe, la sociedad cae en las garras del gobierno maligno de uno. Este soberano corrupto gobierna en forma ilegal ya que lo hace sólo a favor de sí mismo o de su clase social, olvidándose del bien común. Así, el gobierno de uno se transforma en TIRANÍA, que sólo trae sufrimiento e injusticia a toda la sociedad. Cuando la tiranía llega a niveles extremos de corrupción, se produce una revolución y nace así el gobierno de unos pocos o sea, de los ricos, pero en beneficio de todas las clases sociales. Por lo tanto, este también es un gobierno benigno (al igual que la monarquía) y es gobierno de unos pocos pero inspirados por una gran ética y patriotismo; y se le llama 
ARISTOCRACIA. En otras palabras, el gobierno de los mejores pero para el beneficio del bien común. (Esta es así la esencia de la República Aristocrática)

Cuando la aristocracia se corrompe, ya que los ricos comienzan a gobernar para beneficio propio y deciden explotar injustamente a la sociedad, nace el gobierno OLIGÁRQUICO también llamado "plutocracia maligna". Después de décadas o siglos de sufrimiento, y ante esta injusticia extrema, el pueblo se revela y nace un gobierno benigno llamado DEMOCRACIA. Este es el gobierno de todos es decir, el gobierno de la mayoría (los pobres) pero que gobiernan en beneficio de todas las clases sociales esto es, para el bien común. (Esta es la esencia de la República Democrática)

Cuando la democracia se corrompe y el pueblo empieza a abusar de la Democracia y pierde sus virtudes éticas, nace la OCLOCRACIA. Este es un gobierno maligno de los pobres con los pobres y sólo para los pobres. La plebe corrupta arruina el erario nacional, cae en prácticas y costumbres hedonistas, deja de trabajar productivamente y despilfarra las riquezas nacionales y arruina al Estado. Como consecuencia de toda esta corrupción y decadencia, la oclocracia destruye el sistema político y la sociedad libre deja de existir y cae en una dependencia extrema. El Estado se transforma en un Estado Fallido, ya que éste, gracias a su debilidad, es fácilmente conquistado y colonizado por un país vecino mejor organizado. En este camino evolutivo de tipo pesimista (se avanza de los bueno a lo malo) la sociedad originalmente libre, termina por dividirse y transformarse en una vulgar colonia dependiente de un Estado más poderoso y mejor organizado.

¿Es posible usar la teoría de la anaciclosis para tratar de entender la marcha teleológica de la sociedad estadounidense? En el caso de ese gran país la historia se inicia en Gran Bretaña con la monarquía benigna de Isabel I que gobernó en el siglo XVI y a éste monarca se suceden una serie de monarcas relativamente benignos que gobiernan Inglaterra hasta el siglo XVII. Estos monarcas facilitaron la colonización de la costa este del continente norteamericano y administraron con relativa sabiduría dichas colonias. Sin embargo, las cosas cambiaron drásticamente para los colonos estadounidenses, ya que la monarquía inglesa gradualmente se transformó en tiranía, para los colonos a mediados del siglo XVIII. Afortunadamente esta tiranía terminó con la revolución americana de 1776. Los Estados Unidos rompen con el imperio británico y crean una república aristocrática benigna. Esta forma de gobierno se extiende por el resto del siglo XVIII y casi todo el siglo XIX. No obstante, a fines del siglo XIX la aristocracia americana inició un acelerado proceso de corrupción valórica. Los descendientes de los pioneros aristocráticos de antaño, son ahora súper ricos y superpoderosos y con control absoluto sobre la sociedad. Y se produjo lo que se ha dicho tantas veces, el poder absoluto corrompe absolutamente. La clase gobernante perdió gran parte de su ética puritana anterior. El estoicismo calvinista fue reemplazado por el hedonismo consumista.

Este gigantesco cambio cultural se constituyó en la base ética y valórica que dio nacimiento a una gran cantidad de crisis financieras y crisis económicas. El deseo de lucro individual desenfrenado fue mucho más importante que el interés nacional y el interés público. Afortunadamente, a principios del siglo XX, esta crisis ética fue sustancialmente reducida por Teodoro Rossevelt y otros líderes del movimiento progresista. Este miembro de la elite aristocrática pudo, con éxito, revertir la corrupción y evitar el cambio de sistema político, logrando así la sobrevivencia de la aristocracia y de la Republica Aristocrática.

Pero el cáncer de la elite era grave y el sistema político volvió a entrar en crisis a finales de los años 20`s del siglo pasado con la llamada sociedad Gilded. Nuevamente, otro representante de la elite aristocrática logró salvar al país, y esta vez fue el presidente Franklin Delano Rossevelt (primo del anterior). Gracias al Estado de Bienestar creado por Rossevelt, el país se recuperó para fines de los años 30’s, y la segunda guerra mundial terminó por curar los problemas y desajustes económicos que aún sobrevivían. El desequilibrio entre oferta y demanda planetaria, se resolvió con la destrucción de millones de empresas comerciales, agrícolas e industriales. Gracias a la destrucción masiva de extensos sectores del mundo y también gracias a su enorme capacidad empresarial, Estados Unidos se transformó en el país más poderoso del planeta. Como producto de la economía mixta y gracias a las intervenciones, regulaciones y controles estatales impuestos en los años 30's y 40’s; los años 50's y 60's fueron la época de oro del sueño americano, y el sistema aristocrático se consolidó y legitimó robustamente. 
No obstante para finales de años 70's del siglo XX, la avaricia y el deseo de lucro desenfrenado empezó a levantar cabeza una vez más, y la elite aristocrática estadounidense inició un acelerado proceso de corrupción ética. A consecuencia de esto, la economía se desrreguló y privatizó a partir de los años 80’s y con todo ello, empezó el enriquecimiento acelerado de la elite. Simultáneamente empezó también el empobrecimiento relativo de la clase media y del proletariado. El cáncer ético se incrementó exponencialmente en los años 90’s y así nació una nueva época Gilded que se consolidó durante los primeros siete años del siglo XXI. La democracia americana solo logro sobrevivir a nivel de gobiernos locales y municipales.

Ahora estamos a las puertas de un cambio paradigmático. Es probable que la tercera corrupción de la elite oligárquica (la tercera es la vencida) no tenga solución. Después de gastar más de un millón de millones de dólares en resolver la actual crisis crediticia, es probable que todo este gasto no sea suficiente para evitar el inicio de una gravísima depresión económica.

Gracias al salvataje estatal programado durante estos días, los bancos podrían empezar a tratar de prestar dinero y una vez más, incentivar artificialmente el consumo. Pero las medidas propuestas no incluyen una política más justa de distribución del ingreso, incluyendo salarios mejores que puedan crear una demanda verdadera y real. Es probable que después del pánico de estos días, el ciudadano promedio se resista a gastar y por lo tanto, se niegue a consumir como antes. Este miedo o fenómeno psicológico se transformaría así en el catalítico que iniciaría un punto de inflexión que dé inicio a una verdadera depresión económica.

Como resultado de todo esto es probable que el senador Obama gane las próximas elecciones, y el partido demócrata controle ambas cámaras del congreso. Una vez en el poder, los nuevos líderes darían inicio a un cambio paradigmático. Es decir, de un gobierno favorable a unos pocos ricos, a un gobierno favorable para la mayoría. El gobierno habría así cambiado de oligarquía a democracia, es decir, el gobierno de la mayoría pero para beneficio de todos.

El futuro presidente y sus sucesores harían muy bien si simultáneamente, con los cambios radicales propuestos, se implementen las medidas necesarias para revivir viejos valores estoicos y puritanos y así evitar la oclocracia y luego, la fatal vuelta a la dependencia colonial. 